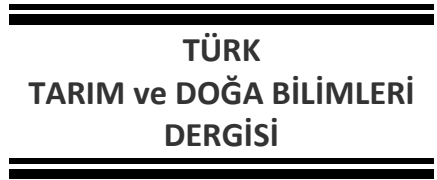

\title{
Araştırma Makalesi \\ Kuraklık Stresine Tolerans Bakımından İki Mürdümük (Latyhrus sativus L.) Genotipinin Değerlendirilmesi
}

\author{
Mehmet ARSLAN*, Elçin AKSU, Emine DOĞAN \\ Akdeniz Üniversitesi Ziraat Fakültesi Tarla Bitkileri Bölümü, Antalya/Türkiye \\ *Sorumlu yazar: mehmetarslan@akdeniz.edu.tr
}

\begin{abstract}
Geliş Tarihi: 28.11.2017
Düzeltme Geliş Tarihi: 01.06.2018

Kabul Tarihi: 05.06.2018

\section{Özet}

Bu araştırma, iki farklı mürdümük çeşidinin kuraklık stresine karşı toleransını belirlemek amacıyla Akdeniz Üniversitesi Ziraat Fakültesi Tarla Bitkileri Bölümü Laboratuarında yürütülmüştür. Bitkisel materyal olarak, Denizli ili, Acıpayam ilçesi, Yumrutaş köyünde uzun yıllardır yetiştirilen yerel bir populasyon ile düşük ODAP içeriğine sahip bir çeşit olarak tescil edilen Ceora çeşidi kullanılmışır. Araştırmada, polietilen glikol-6000 (PEG 6000) kullanılarak $0,-2,-4,-6,-8,-9,8$ bar su tutma gücüne sahip solüsyonlar ile 6 farklı kuraklık stresi oluşturulmuştur. Deneme 2 faktörlü ve 4 tekerrürlü tesadüf parselleri deneme desenine göre kurulmuştur. Çalışma sonucunda -8 ve $-9,8$ bar kuraklık seviyesinde çimlenme sağlanamamış, diğer seviyelerde başarılı çimlenme sağlanmıştır. Elde edilen sonuçlara göre, çimlenme oranı \%90-100, kökçük uzunluğu 30.05-67.87 mm, sapçık uzunluğu 9.07$32.60 \mathrm{~mm}$, kökçük yaş ağılığı 170.25-918.65 mg ve sapçık yaş ağırlığı 113.00-792.10 mg arasında değişmiştir. Sonuçta, 2 genotip arasında çimlenme oranı bakımından fark oluşmazken, fide gelişimi yönünde önemli fark bulunmuş ve yerel populasyonun kuraklığa daha toleranslı olduğu görülmüştür.
\end{abstract}

Anahtar kelimeler: Mürdümük, Lathyrus sativus L., çimlenme, PEG-6000, kuraklık stresi.

\section{Assessment of Two Grass Pea (Lathyrus sativus L.) Varieties in term of Tolerance to Drought Stress}

\begin{abstract}
This research was carried out to determine the tolerance of two different varieties of grass pea (Latyhrus sativus L.) against drought stress in the Laboratory of Field Crops Department of the Faculty of Agriculture, Akdeniz University. A local landrace, which has been grown for many years in Yumrutaş village of Acıpayam district in Denizli province and the registered Ceora variety with the low ODAP content was used as plant materials. In the study, six different drought stresses were formed with solutions, which have $0,-2,-4,-6,-8,-$ 9.8 bar water holding power respectively using polyethylene glycol-6000 (PEG 6000). The trial was established according to 2-factorial and 4-replicate randomized trial design. As a result of the study, germination was not observed at -8 and -9.8 bar drought level, while successful germination was observed in other levels. According to the results obtained, germination rate, root length, stalk length, rootlet fresh weight and stalk fresh weight ranged from \%90-100, 30.05-67.87 mm, 32.60-9.07 mm, 170.25-918.65 mg and 13.00-792.10 mg respectively. As a result, while there was no difference in germination rate between 2 genotypes, it was found to be significant difference in seedling growth and local landrace was seen to be more tolerant.
\end{abstract}

Key words: Grass pea, Lathyrus sativus L., germination, PEG-6000, drought stres.

Giriş

Mürdümük, en az düzeyde yetiştiricilik ihtiyaçları ile en kötü iklimsel koşullar altında dahi yeterli seviyede verime sahip olmasından dolayı Hindistan, Bangladeş, Nepal ve Etiyopya 
gibi ülkelerde giderek artan miktarlarda yetiştirilmektedir (Campbell ve ark., 1994). Ülkemizde ise her bölgede yetişme potansiyeli olan ama büyük oranda Güneydoğu Anadolu Bölgesi'nde yetiştiriciliği yapılan mürdümüğün, geçmiş dönemlerde enerji ihtiyacı yüksek çift süren hayvanlara danelerinin yedirildiği bilinmektedir. Genellikle yerel çeşitlerle yetiştiriciliği yapılan mürdümük, kurak geçen yıllarda da insan beslenmesinde de değerlendirilmektedir (Başaran ve ark., 2007; Arslan, 2016). Kuraklığa, aşırı yağışlara ve su birikmesine toleranslı olan mürdümüğün ekim nöbetine kolayca dahil edilerek, kaliteli kaba yem üretimine katkı sağlayacağı ve aynı zamanda toprağa biyolojik olarak azot fikse ederek iyileştirilmesine katkıda bulunacağı bildirilmektedir (Sayar ve Han, 2014). Bununla beraber, mürdümük bitkisi kuraklığa, soğuklara ve tuz stresine toleranslı olduğu gibi hastalık, zararlı ve yabancı otlara karşı rekabet yeteneği yüksek olup, diğer baklagillerle karşılaştırıldığında, birçok hastalık ve zararlıya karşı daha dayanıklıdır (Campbell, 1997; Das, 2000; Vaz Patto ve ark., 2006). Mürdümük, yıllık olarak 10.8-12.5 kg/da azotu toprağa bağlayabilmektedir (Noto ve ark., 2001). Toprağa fikse edilen bu azot, hem bitkinin kendi azot ihtiyacını karşılamakta hem de daha sonraki dönemlerde yetiştirilecek olan bitkilere azot kaynağı bırakmaktadır. Bu sayede toprağın azot dengesinin ayarlanmasında yarar sağlamaktadır (Kumar ve ark., 2011; Talukdar, 2011).

Mürdümük besin değeri bakımından bezelye (Pisum sativum) ve bakla (Vicia faba) ile yakın olmasına rağmen daha düşük yağ ve daha yüksek nişasta içermektedir. Yaklaşık olarak \%25-27 oranında protein içeren mürdümük, bu yönüyle bezelye ve bakladan yüksek fakat soya fasulyesinden daha düşük içeriğe sahiptir (Hanbury ve ark., 2000). Öte yandan, amino asit içeriği bakımından bir kıyaslama yapıldığında, diğer baklagillerle uyumlu olmakla beraber, lysine içeriği bakımından daha zengin, sülfür amino asitleri açısından yetersiz durumdadır (Grela ve ark., 2010, Arslan, 2017a).

Mürdümük bitkisi yukarıda belirtilen önemli özelliklerinin yanında, en önemlisi ODAP ( $\beta$-N-oxalyl-L- $\alpha, \beta$-diaminopropionic asit) olarak bilinen, beslenme açısından sakıncalı bazı serbest amino asitler içermektedir (Yan ve ark., 2006; Arslan ve ark., 2017). ODAP protein yapısında olmayan serbest bir aminoasittir. Merkezi sinir sistemleri üzerinde yıkıcı etkisi nedeniyle, motor nöronlarda fonksiyon bozukluğu oluşturmakta ve lathyrism olarak bilinen hastalığa sebep olmaktadır (Xu ve ark., 2017). Mürdümük tanelerinin içerdiği ODAP miktarı, genellikle genetik olarak kontrol edilmesinin yanında, çevresel ve iklimsel olaylardan da önemli ölçüde etkilenebilmektedir (Campbell, 1997; Grela ve ark., 2010). Genellikle kuraklığa toleransın yüksek olduğu durumlarda ODAP içeriği de yüksek olmaktadır (Grela ve ark., 2010; Vaz Patto ve ark., 2006).

Dünyada önemli derecede bir iklim değişikliği meydana gelmekte ve konu uzmanları ülkemizin de yer aldığı büyük alanlar için kuraklık riskine dikkat çekmektedir. (Rosenzweig ve ark., 2001). Kuraklık, uzun yıllar ortalamasından daha düşük seviyede gerçekleşen yağış miktarından dolayı tarla ve su kaynaklarının olumsuz etkilenme durumu olarak bilinmektedir. Tarımsal anlamda kuraklık ise bir yıl içerisinde düşen toplam yağış miktarı değil, tarlaya ekilen bir bitkinin gelişme periyodunda kökleri ile alabildiği su miktarı ile alakalı bir kavramdır. Gelişme periyodunda su kısıtlılığı çeken bitkilerde, gelişme ve dolayısıyla verimsel anlamda kayda değer kayıplar yaşanmaktadır (Katerji ve ark., 1998; Öztürk, 2015). Türkiye'de yaklaşık 4.5-5 milyon ha tarımsal alan yıllık 400 $\mathrm{mm}$ 'den daha az yağış almaktadır. Bu nedenle tarımsal alanlarımızın büyük bir bölümünde kuru tarım yapılmak zorundadır. Zira, bazı yıllarda uzun süren kurak dönemler yaşanmakta ve bu dönemlerdeki tarımsal üretim miktarında ve kalitesinde ciddi oranlarda kayıpları meydana gelmektedir. Bu nedenle, kuru tarımın yapıldığı alanlarda su kısıtlılığına toleranslı bitkilerin tercih edilmesi kuraklığa karşı alınacak en ekonomik ve etkili önlem olarak bilinmektedir (Arslan, 2017b; Safi ve ark., 2013). Kuraklığa yüksek derecede toleranslı bir bitki olan mürdümük birçok araştırmacının dikkatini çekmiştir. Safi ve ark. (2013), mürdümüğün ot üretim amaçlı yetiştirildiğinde su kısıtıılığına nötr durumda olduğunu, ancak tohum üretimi açısından son derece toleranslı olduğunu bildirmişlerdir. Gheidary ve ark. (2017), ise mürdümüğün çimlenme aşamasında tuzluluğa ve kuraklığa etkisini araştırdıkları çalışmalarında, bitkinin kurak ve yarı-kurak alanlarda su kısıtlılığına toleranslı olduğunu ve bu toleransın priming uygulamaları ile daha da arttırılabileceğini bildirmektedirler.

Küresel iklim değişikliğinin beraberinde getirdiği risklerle birlikte, fazla miktarda kimyasal maddelerin kullanıldığı tarımsal üretimler doğal kaynaklarda önemli düzeylerde 
kirlilik tehlikesi meydana getirmektedir. İçerdiği nörotoksinlerden dolayı bir dönem üretiminin yasaklandığı mürdümük bitkisi, artık güvenilir sınırlar içerisinde ODAP içeren yeni çeşitler sayesinde ve bilinen birçok yetiştiricilik avantajlarıyla birlikte bütün dünyada ilgi çekmektedir. Yürütülen bu çalışmada, ODAP içeriği düşük olduğu bilinen Ceora çeşidi ile ODAP içeriği bilinmeyen yerel bir populasyonun PEG-6000 ile oluşturulan kuraklık stresi koşullarında çimlenme özellikleri incelenerek tolerans düzeyleri ortaya konmuştur.

\section{Materyal ve Yöntem}

Bu araştırma Akdeniz Üniversitesi Ziraat Fakültesi Tarla Bitkileri Bölümü Laboratuarında gerçekleştirilmiştir. Denemede, bitkisel materyal olarak Denizli ili, Acıpayam ilçesi, Yumrutaş köyünde uzun yıllardır kullanılmakta olan yerel bir populasyonun tohumları ve düşük ODAP içeriğine sahip mürdümük çeşidi olarak tescil edilmiş olan Ceora (Siddique ve ark., 2006) çeşidinin tohumları kullanılmıştır. Yerel çeşidin tohumları koyu kahverengi olup 100 tane ağırlığı $14.38 \mathrm{~g}$ olarak tespit edilmiştir. Ceora çeşidinin tohumlar ise beyaz renkli ve 100 tane ağırlığı $11.06 \mathrm{~g}$ olarak ölçülmüştür. Mürdümük çeşitlerinin kuraklık stresine karşı toleranslarını belirlemek amacıyla PEG 6000 kullanılarak 0, 2, 4, 6, 8, 9,8 bar su tutma gücüne sahip solüsyonlar ile 6 farklı kuraklık stresi oluşturulmuştur. Kuraklık seviyeleri için osmotik potansiyeller Michel ve Kaufmann (1973)'ın önerdiği şekilde ayarlanmıştır. PEG yüksek molekül ağırlığına sahip bir kimyasal madde olduğundan ortamdaki su alımını düzenleyerek istenilen düzeyde kuraklık stresi yaratmaktadır. Bitki kökleriyle alınmayan ve dolayısıyla toksik etki yaratmayan PEG-6000, karıştırıldığı çözeltilerde oksijenin zamanla azalmasına neden olmaktadır. Çimlendirme ortamı olarak kullanılan petrilerde oksijen azalışının olumsuz etkileri ise, çimlendirme kağıtlarının 3-4 gün arayla değiştirilmesi sayesinde ortadan kaldırılmaktadır (Çarpıcı ve Erdel, 2015).

Deneme tesadüf parselleri deneme deseninde iki faktörlü ve dört tekerrürlü olarak kurulmuştur. Çimlendirmeler için toplam 48 adet $9 \mathrm{~cm}$ 'lik petri kapları kullanılmıştır. Büyüklükleri eşit düzeyde olan 10 adet, tohum içerisinde çift katlı çimlendirme kağıdı olan petri kaplarına yerleştirilmiştir. Daha sonra tohumların üzerine farklı miktarlarda PEG-6000 içeren solüsyonlardan $10 \mathrm{ml}$ dökülmüş ve petri kaplarının etrafı buharlaşmayı önlemek amacıyla parafilm ile sarılmıştır. Hazırlanan petri kapları 14 saat ışıklı, 10 saat karanlık, $\% 70$ nem ve $20^{\circ} \mathrm{C}$ sıcaklık koşullarına ayarlı çimlendirme kabinine yerleştirilmiştir. Petriler çimlenme kabininde 10 gün süreyle tutulmuştur (Gheidary ve ark., 2017).

Denemede her gün aynı saatte gözlemler yapılmış ve kökçük uzunluğu 2 mm'yi geçen tohumlar çimlenmiş olarak kabul edilmiştir. 10. günün sonunda toplam çimlenen tohumlar sayılarak çimlenme yüzdesi (\%) belirlenmiştir (Scott ve ark., 1984). Çimlenmenin 10. gününde her bir petri kabındaki bitkilerde sapçık ve kökçük uzunlukları, kökçük ve sapçık yaş ağırıkları belirlenmiştir.

Araştırmada elde edilen verilerin istatistiksel olarak değerlendirilmesinde, 4 tekerrürlü tesadüf parselleri deneme desenine göre varyans analizi, grupların belirlenmesinde ise Duncan çoklu karşılaştırma testi uygulanmıştır. $\mathrm{Bu}$ amaçla SPSS paket programından yararlanılmıştır.

\section{Bulgular ve Tartışma}

İki farklı mürdümük genotipinin farklı seviyelerdeki kuraklık stresindeki çimlenme özelliklerinin incelendiği bu çalışmada, $0,-2,-4$ ve -6 bar seviyelerinde çimlenme sağlanmış fakat -8 ve -9.8 bar kuraklık stresi seviyesinde çimlenme sağlanamamıştır. Çalışmada elde edilen çimlenme oranı, kökçük uzunluğu, sapçık uzunluğu, kökçük yaş ağırlığı ve sapçık yaş ağırlığı verilerine varyans analizi uygulanmış ve sonuçları Çizelge 1'de verilmiştir. Çizelge 1 incelendiğinde, çimlenme oranı bakımından genotipler ve genotip $\mathrm{x}$ kuraklık interaksiyonu arasında önemli bir fark oluşmazken, kuraklık stresi bakımından istatistiki anlamda \%1 düzeyinde bir fark tespit edilmiştir. Benzer farklılıklar kökçük uzunluğunda ve sapçık uzunluğunda da bulunmuştur. Kökçük yaş ağırlığı ise genotip, kuraklık stresi ve genotip $x$ kuraklık stresi interaksiyonu bakımından \%1 düzeyinde önemli bulunmuştur. Sapçık yaş ağırlığı değerleri bakımından da genotipler $(p<0.05)$, kuraklık stresi ve genotip * kuraklık stresi arasında önemli $(p<0.01)$ fark oluşmuştur.

\section{Çimlenme oranı}

Mürdümük genotiplerinin farklı düzeylerdeki kuraklık stresi koşullarındaki çimlenme oranları \%90-100 arasında değişen oranlarda tespit edilmiştir (Çizelge 1). Ayrıca, her iki çeşit de -8 ve -9.8 bar kuraklık stresi altında çimlenme göstermemiştir. Hem yerel 
populasyon hem de Ceora çeşidinde kuraklık stresi arttıkça, çimlenme oranları da azalmış fakat bu oranlar farklı bir Duncan grubu oluşturmamıştır. Çimlenme oranlarındaki azalma, \%90 oranında çimlenme gösteren yerel çeşitte daha fazla olmuştur.

Saxena ve ark. (1993), tarımsal üretim açısından kuraklığın iki temel etkisinin bulunduğunu bildirmektedir. Bunlar istenilen bitki çıkışını sağlanamaması ve toprakta istenilenden daha az su bulunması nedeniyle gelişme ve verimde azalma olarak ifade edilmektedir. Araştırıcılara göre, çıkışta görülen düzensizlik, istenen bitki sıklığını elde edilememesine, bitkilerin çiçeklenme ve olgunlaşmasında düzensizliklere, verimin düşmesine, hasatta olgunlaşma düzensizliklerine neden olabilmektedir. Birçok mera ve yem bitkisinde tohum çimlenmesi ve erken fide gelişimi bitkinin büyümesinde ve gelişmesinde çevresel stres faktörlerine karşı en hassas olduğu aşamalardır (Gheidary ve ark., 2017). Bu çalışmada elde edilen sonuçlar araştırmacıların ifade ettiği hassasiyetler ışığında değerlendirildiğinde, mürdümük genotiplerinin orta seviyedeki kuraklık stresinde bile başarılı bir çimlenme ve fide gelişimi özelliğine sahip olduğunu göstermektedir.

$\mathrm{Bu}$ denemede elde edilen çimlenme oranları, Gheidary ve ark. (2017), Safi ve ark. (2013), Ayan ve ark. (2005), Fallahi ve ark. (2015)'nın mürdümükte, Gürbüz ve ark. (2009)'nın nohutta (Cicer arietinum L.), MurilloAmador ve ark. (2002)'nın da börülcede (Vigna unguiculata L.) kuraklık stresinin çimlenmeye olan etkisini araştırdıkları çalışma sonuçları ile uyumludur.

Çizelge 1. İki faklı mürdümük genotipinin farklı kuraklık stresi koşullarında elde edilen çimlenme oranı, kökçük uzunluğu, sapçık uzunluğu, kökçük yaş ağırlığı, sapçık yaş ağırlığı ortalamaları.

\begin{tabular}{|c|c|c|c|c|c|c|}
\hline Genotipler & $\begin{array}{l}\text { Kuraklık } \\
\text { stresi } \\
\text { (bar) }\end{array}$ & $\begin{array}{l}\text { Çimlenme } \\
\text { oranı (\%) }\end{array}$ & $\begin{array}{l}\text { Kökçük } \\
\text { uzunluğu } \\
(\mathrm{mm})\end{array}$ & $\begin{array}{c}\text { Sapçık } \\
\text { uzunluğu } \\
(\mathrm{mm})\end{array}$ & $\begin{array}{c}\text { Kökçük yaş } \\
\text { ağırlığı } \\
\text { (mg/bitki) }\end{array}$ & $\begin{array}{c}\text { Sapçık yaş } \\
\text { ağırlığı } \\
\text { (mg/bitki) }\end{array}$ \\
\hline \multirow{4}{*}{$\begin{array}{c}\text { Yerel } \\
\text { populasyon }\end{array}$} & 0 & $97.50 a^{1}$ & $67.87 \mathrm{a}$ & $32.40 \mathrm{a}$ & $918.65 \mathrm{a}$ & $792.10 \mathrm{a}$ \\
\hline & -2 & $92.50 \mathrm{a}$ & $62.70 a b$ & $32.60 \mathrm{a}$ & 790.35 a & $513.60 \mathrm{~b}$ \\
\hline & -4 & $95.00 \mathrm{a}$ & 40.94 bc & $13.43 \mathrm{bcd}$ & 390.40 bc & $309.88 \mathrm{~cd}$ \\
\hline & -6 & $90.00 \mathrm{a}$ & 32.04 bc & $29.41 \mathrm{ab}$ & 243.18 bc & $113.00 \mathrm{fg}$ \\
\hline \multirow{4}{*}{ Ceora } & 0 & $100.00 \mathrm{a}$ & $42.57 \mathrm{abc}$ & $25.97 \mathrm{abc}$ & $463.00 \mathrm{~b}$ & $482.20 \mathrm{bc}$ \\
\hline & -2 & $97.50 \mathrm{a}$ & $41.78 a b c$ & $22.00 \mathrm{abc}$ & 390.48 bc & $476.20 \mathrm{bc}$ \\
\hline & -4 & $97.50 \mathrm{a}$ & $39.80 \mathrm{bc}$ & $21.07 \mathrm{abc}$ & 383.68 bc & $347.05 \mathrm{~cd}$ \\
\hline & -6 & $95.00 \mathrm{a}$ & $30.05 \mathrm{c}$ & $9.07 \mathrm{~cd}$ & $170.25 \mathrm{~cd}$ & 173.28 ef \\
\hline Genotip (G) & & öd & $*$ & $*$ & $* *$ & $*$ \\
\hline $\begin{array}{l}\text { Kuraklık } \\
\text { Stresi (KS) }\end{array}$ & & $* *$ & $* *$ & $* *$ & $* *$ & $* *$ \\
\hline $\mathrm{G} * \mathrm{KS}$ & & öd & $*$ & $*$ & $* *$ & $* *$ \\
\hline
\end{tabular}

1: Aynı sütunda yer alan ve aynı harfi taşıyan değerler arasında fark önemli değildir $(p<0.05)$.

*: 0.05 seviyesinde önemlidir. ${ }^{* *}$ : 0.01 seviyesinde önemlidir. öd: önemli değil.

\section{Kökçük uzunluğu}

Mürdümük genotiplerinde farklı seviyelerdeki kuraklık stresi koşullarında elde edilen kökçük uzunluğu değerlerine ait ortalamalar 67.87 ile $30.05 \mathrm{~mm}$ arasında değişmektedir (Çizelge 1). Kuraklık stresi artışına bağlı olarak kökçük uzunluğu değerleri azalma göstermiş ve çok sayıda farklı Duncan grubu oluşmuştur. Dikkat çekici başka bir nokta ise kontrol uygulamasında yerel çeşidinin kökçük uzunluğunun Ceora çeşidine göre daha yüksek olmasıdır. Fakat -6 bar kuraklık stresi uygulamasında her iki genotip de yakın uzunlukta kökçük geliştirmiştir. Baklagillerde farklı kuraklık seviyelerinde kökçük uzunluğunda azalmanın olduğu birçok araştırıcı tarafından (Kaya ve ark., 2006; Çarpıcı ve Erdel, 2015; Fallahi ve ark., 2015; Gheidary ve ark., 2017) tespit edilmiştir.

\section{Sapçık uzunluğu}

Çimlenme aşamasında kuraklık stresine maruz kalan mürdümük tohumlarının oluşturduğu sapçık uzunlukları 9.07 ile 32.60 $\mathrm{mm}$ arasında değişmekte olup kuraklık stresinin dozu arttıkça sapçık uzunluğu azalmıştır (Çizelge 1). Bu özellik bakımından dikkat çekici olan başka bir durum, yerel populasyonun sapçık uzunluğu 
değerlerinin Ceora'nın değerlerinden daha yüksek olmasıdır. PEG-6000 ile oluşturulan kuraklık stresi çimlenme oranı ve erken fide gelişimini olumsuz etkilediği, hatta kökçük ve sapçık yaş ve kuru ağırlıkları ile kökçük ve sapçık uzunluklarını da azalttığı Kaya ve ark. (2006), Okçu ve ark. (2005), Gheidary ve ark. (2017) ve Farooq ve ark. (2009) tarafindan bildirilmektedir.

\section{Kökçük yaş ağırlığı}

Kuraklık stresi altında çimlenen mürdümük genotiplerinin kökçük yaş ağırlıklarına ait veriler incelendiğinde, yerel populasyonda 243.18 ile $918.65 \mathrm{mg}$ arasında, Ceora çeşidinde ise 170.25 ile $463.00 \mathrm{mg}$ arasında değişen değerlerin elde edildiği görülmektedir (Çizelge 1). Kuraklık stresi arttıkça çimlenen mürdümük tohumlarında oluşan kökçük yaş ağırlığı miktarlarında azalma meydana gelmiştir. Fallahi ve ark. (2015), ozmotik stres altında çimlenen mürdümük tohumlarında kökçük kuru ağırlığını 3.5-6.6 $\mathrm{mg} /$ bitki arasında değişen miktarlarda tespit etmişlerdir. Bizim çalışmamızda yaş kökçük ve sapçık ağırlıkları ölçülmüş olup kuru ağırlıklarının da benzer düzeylerde olacağı tahmin edilmektedir.

\section{Sapçık Yaş Ağırlığı}

Mürdümük genotiplerinin kuraklık stresi koşullarında çimlendirilmesi sonucu elde edilen sapçık yaş ağırlığı yerel populasyonda 113.00 ile $792.10 \mathrm{mg}$ arasında, Ceora çeşidinde ise $\mathbf{1 7 3 . 2 8}$ ile $482.20 \mathrm{mg}$ arasında değişmektedir (Çizelge 1). Bu değerlerden açıkça görüldüğü gibi yerel populasyon (113.00 mg) Ceora çeşidine (173.28 $\mathrm{mg}$ ) göre kuraklık stresinden daha çok etkilenmiştir. Fallahi ve ark. (2015), ozmotik stres altında çimlenen mürdümük tohumlarında kökçük kuru ağırlığını 2.0-4.0 mg/bitki arasında değişen miktarlarda bulurken, $-8,-10$ ve -12 bar ozmotik stres altında çimlenme sağlanmış fakat çok düşük düzeyde fide gelişimi sağlandığını bildirmiştir. Bizim çalışmamızda, bu sevilerindeki kuraklık stresinde tohumlarda su alarak şişme görülmüş fakat kökçük çıkışı olmadığından çimlenme sağlanamamıştır. Çalışmamızda elde edilen gerek kökçük gerekse sapçık ağırlıkları Gheidary ve ark. (2017), Fallahi ve ark. (2015) ve Farooq ve ark. (2009)'nın ifade ettiği bitki fide ağırlıkları ile benzerlik göstermektedir.

\section{Sonuç ve Öneriler \\ PEG-6000 ile oluşturulan farklı} seviyelerdeki kuraklık stresi koşullarında çimlendirilen 2 farklı mürdümük genotipi, bu strese karşı farklı tepkiler vermiştir. Genotipler arasında çimlenme oranları bakımından önemli bir fark oluşmamıştır. Fakat, iri tohumlu ve ODAP içeriği bilinmeyen yerel populasyon, düşük ODAP içeriği ile tescil edilmiş olan, daha ufak beyaz renkli tohumlara sahip Ceora çeşidine göre daha iyi erken fide gelişimi göstermiştir. ODAP'ın hem genetik olarak kontrol edildiği hem de çevresel faktörlerden etkilendiği bilinmektedir. Bununla beraber bir mürdümük genotipinin kuraklığa toleransının ne kadar fazla ise ODAP içeriğinin de o kadar yüksek olduğu da birçok araştırıcı tarafından ifade edilmiştir. Buradan hareketle yerel çeşidin ODAP içeriğinin Ceora çeşidine göre daha yüksek olması tahmin edilebilir. Çalışmada dikkat çekici bir başka nokta da -8 ve -9.8 bar kuraklık stresi koşullarında tam çimlenmenin elde edilememesi olmuştur. Bu çalışma sonucuna göre mürdümük bitkisinin çimlenme döneminde kuraklığa karşı iyi düzeyde toleranslı olduğu söylenebilir.

\section{Kaynaklar}

Arslan, M. 2016. Importance and current situation of grass pea (Lathyrus sativus L.) in forage crops production of Turkey. Turkish Journal of Agricultural and Natural Sciences, 3(1): 17-23.

Arslan, M. 2017a. Diversity for vitamin and amino acid content in grass pea (Lathyrus sativus L.). Legume Research, 40(5): 803810.

Arslan, M. 2017b. Fatty acid characteristics of grass pea (Lathyrus sativus) in an East Mediterranean environment. Cogent Chemistry, 3: 1296748.

Arslan, M., Oten, M., Erkaymaz, T., Tongur, T., Kilic, M., Elmasulu, S., Cinar, A. (2017). $\beta$ $\mathrm{N}$-oxalyl-L-2,3-diaminopropionic acid, Lhomoarginine and asparagine contents in the seeds of different genotypes Lathyrus sativus L. as determined by UHPLC-MS/M. International Journal of Food Properties, (accepted manuscript), Article DOI: 10.1080/10942912.2017.1289961.

Ayan, İ., Başaran, U., Acar, Z., Mut, H. 2005. Doğal olarak yetişen bazı mürdümük (Lathyrus sp.) türlerinde depolama süresi ve mekanik aşındırmanın tohumların çimlenme oranları üzerine etkileri. 
Türkiye II. Tohumculuk Kongresi, 9-11 Kasım 2005, Adana. s. 230-235.

Başaran, U., Acar, Z., Aşçı, Ö.Ö., Mut, H., Ayan, I., 2007. Mürdümük (Lathyrus sp.) türlerinin önemi, tarımda kullanım olanakları ve zararlı madde içerikleri. OMÜ Ziraat Fakültesi Dergisi, 22(1): 139-148.

Campbell, C.G. 1997. Grass Pea (Lathyrus sativus L.) promoting The Conservation and Use of Underutilized and Neglected Crops. Vol. 18. International Plant Genetic Resources Institute, Rome, Italy.

Campbell, C.G., Mehra, R.B., Agrawal, S.K., Chen, Y.Z., Abd-El-Moneim, A.M., Khawaja, H.I.T., Yadav, C.R., Tay, J.U., Araya, W.A. 1994. Current status and future strategy in breeding grass pea (Lathyrus sativus). Euphytica 73: 167-175.

Çarpıcı, E.B., Erdel, B. 2015. Bazı yonca çeşitlerinde (Medicago sativa L.) kuraklık stresinin çimlenme özellikleri üzerine etkisi. Derim, 32(2): 201-210.

Das, N.R. 2000. Lathyrus sativus in Rainfed Multiple Cropping Systems in West Bengal. Indian Review. Lathyrus Lathyrism Newsletter 1: 25-27.

Fallahi, H.R., Fadaeian, G., Gholami, M., Daneshkhah, O., Hosseini, F.S., Aghhavani-Shajari, M., Samadzadeh, A. 2015. Germination response of grasspea (Lathyrus sativus L.) and arugula (Eruca sativa L.) to osmotic and salinity stresses. Plant Breeding and Seed Science, 71: 97108.

Farooq, M., Wahid, A., Kobayashi, N., Fujita, D., Basra, S.M.A. 2009. Plant Drought stress: effects, mechanisms and management. Agron. Sustain. Dev., 29: 185-212.

Gheidary, S., Akhzari, D., Pessarakli, M. 2017. Effects of salinity, drought, and priming treatments on seed germination and growth parameters of Lathyrus sativus L.. Journal of Plant Nutrition, 40(10): 15071514.

Grela, E.R., Rybinski, W., Klebaniuk, R., Matras, J. 2010. Morphological characteristics of some accessions of grass pea (Lathyrus sativus L.) grown in Europe and nutritional traits of their seeds. Genetic Resource and Crop Evoluation 57: 693.701.

Gürbüz, A., Kaya, M., Türkan, A.D., Kaya, G., Kaya, M.D., Çiftçi, C.Y. 2009. Bazı Nohut (Cicer arietinum L.) Çeşitlerinde Tane İriliği ve Kuraklık Stresinin Çimlenme
Özelliklerine Etkisi. Akdeniz Üniv. Ziraat Fak. Derg., 22(1): 69-74.

Hanbury, C.D., White, C.L., Mullan, B.P., Siddique, K.H.M. 2000. A review of the use and potential of Lathyrus sativus $L$. and $L$. cicera L. grain for animal feed. Animal Feed Science and Technology 87: 1-27.

Katerji, N., Van Hoorn, J.W., Hamdy, A., Mastrorilli, M., Karam, F. 1998. Salinity and drought, a comparison of their effects on the relationship between yield and evapotranspiration. Agricultural Water Management, 36(1998): 45-54.

Kaya, M.D., Okçu, G., Atak, M., Çıkılı, Y., Kolsarıcı, Ö. 2006. Seed treatments to overcome salt and drought stress during germination in sunflower (Helianthus annuus L.). Europ. J. Agronomy, 24: 291295.

Kumar, S., Bejiga, G., Ahmed, S., Nakkoul, H., Sarker, A. 2011. Genetic improvement of grass pea for low neurotoxin ( $\beta$-ODAP) content. Food and Chemical Toxicology 49: 589-600.

Michel, B.E., Kaufmann, M.R. 1973. The osmotic potential of polyethylene glycol 6000 . Plant Physiology, 51: 914-16.

Murillo-Amador, B., Lopez-Aguilar, R., Kaya, C., Larrinaga-Mayoral, J., Flores-Hernandez, A. 2002. Comparative effects of $\mathrm{NaCl}$ and Polyethylene glycol on germination, emergence and seedling growth of cowpea. J. Agronomy and Crop Science, 188: 235-247.

Noto, F., Poma, I., Gristina, L., Venezia, G., Ferrotti, F. 2001. Bioagronomic and qualitative characteristics in Lathyrus sativus lines. In: Proceedings 4th European Conference on Grain Legumes (eds. AEP), 8-12 July 2001, Cracow, Poland. p.183.

Okçu, G., Kaya, M.D., Atak, M. 2005. Effects of Salt and drought stresses on germination and seedling growth of pea (Pisum sativum L.), Turk. J. Agr. For. 29: 237-242.

Öztürk, N.Z. 2015. Bitkilerin kuraklık stresine tepkilerinde bilinenler ve yeni yaklaşımlar. Türk Tarım-Gıda Bilim ve Teknoloji Dergisi, 3(5): 307-315.

Rosenzweig, C., Iglesias, A., Yang, X.B., Epstein, P.R., Chivian, E. 2001. Climate change and extreme weather events: implications for food production, plant diseases, and 
pests. Global Change and Human Health, 2 (2): 90-104.

Safi, S., Şimşek, H., Ünlükara, A. 2013. Su ve tuzluluk stresinin Mürdümük'te (Lathyrus sativus L.) bitki büyüme, gelişme, verim ve su tüketimi üzerine etkilerinin belirlenmesi. Gaziosmanpaşa Üniversitesi Ziraat Fakültesi Dergisi, 30(1): 1-12.

Sayar, M.S., Han, Y. 2015. Mürdümük (Lathyrus sativus L.) hatlarının tohum verimi ve verim komponentlerinin belirlenmesi ve GGE BIPLOT analiz yöntemiyle değerlendirilmesi. Tarım Bilimleri Dergisi, 21: 78-92.

Saxena, N.P., Johansen, C., Saxena, M.C., Silim, S.N. 1993. Selection for drought and salinity tolerance in cool-season food legumes. In: K.B. Singh and M.C. Saxena Eds. Breeding for stress tolerance in coolseason food legumes. United Kingdom, p.245-270.

Scott, S.J., Jones, R.A., Williams, W.A. 1984. Review of data analysis methods for seed germination. Crop Science, 24: 11921199.

Siddique, K.H.M., Hanbury, C.L., Sarker, A. 2006. Registration of 'Ceora' grass pea. Crop Science, 46: 986.

Talukdar, D. 2011. Morpho-Physiological responses of grass pea (Lathyrus sativus) genotypes to salt stress at germination and seedling stages. Legume Research, 34 (4): 232-241.

Yan, Z.Y., Spencer, P.S., Li, Z.X., Liang, Y.M., Wang, Y.F., Wang, C.Y., Li, F.M. 2006. Lathyrus sativus (grass pea) and its neurotoxin ODAP. Phtytochemistry 67: 107-121.

Vaz Patto, M.C., Skiba, B., Pang, E.C.K., Ochatt S.J., Lambein, F., Rubiales, D. 2006. Lathyrus improvement for resistance against biotic and abiotic stresses: From classical breeding to marker assisted selection. Euphytica (2006) 147: 133-147.

Xu, Q., Liu, F., Jez, J.M., Krishnan, H.B. 2017. $\beta$ $\mathrm{N}$-oxalyl-L-2,3-diaminopropionic acid ( $\beta$ ODAP) Content in Lathyrus sativus: the integration of nitrogen and sulfur metabolism through $\beta$-cyanoalanine synthase. Int. J. Mol. Sci.,18: 526. 